\title{
Joy in Work for Clinicians and Staff: Identifying Remedial Predictors of Burnout from the Mini $Z$ Survey
}

\author{
Niharika Khanna, MD, MBBS, DGO, Russ Montgomery, PhD, and \\ Elena Klyushnenkova, PhD
}

Purpose: The CMS Transforming Clinical Practice Initiative (TCPI) provided coaching and learning support to practices during transition to new models of value-based care. Maryland ambulatory practices participated in the Garden Practice Transformation Network (GPTN) as a part of the TCPI. During practices assessment, we measured prevalence of burnout and identified its remediable predictors among GPTN-Maryland practices.

Methods: A modified Mini $\mathrm{Z}$ tool survey was distributed among clinicians and staff in November 2018 - July 2019. Association between presence of burnout and burnout drivers was assessed using a Generalized Estimating Equation regression model for ordinal outcome.

Results: Data from 166 responses were analyzed. Prevalence of burnout symptoms was 22\%, with 35\% enjoying their work. A 100-point Time Constraints/Teamwork (T/T) score was constructed using factors significantly associated with burnout symptoms. T/T score increase by 1 unit was associated with $10 \%$ increase in the odds of moving from the group experiencing burnout or stress to the group who found 'joy in work' $(\mathrm{OR}=1.1,95 \% \mathrm{CI} 1.07,1.13, \mathrm{p}<0.0001)$.

Conclusions: The Mini Z-derived T/T score could be useful for quick assessment of the degree of burnout and identifying burnout drivers related to effective organizational structure and supportive teamwork in practice personnel. (J Am Board Fam Med 2020;33:357-367.)

Keywords: Family Physicians, Maryland, Prevalence, Primary Health Care, Professional Burnout, Workforce

\section{Introduction}

New models of value-based care include quality measurement and improvement supported by new workflows that redefine physicians' roles within the practice team. Physicians have reacted to the delivery of patient care impacted by new models such as practice transformation, with reduction in physician burnout. ${ }^{1}$

This article was externally peer reviewed.

Submitted 19 December 2019; revised 5 March 2020; accepted 10 March 2020.

From the Department of Family and Community Medicine, University of Maryland School of Medicine, Baltimore (NK and EK); Discern Consulting, Baltimore, Maryland (RM).

Funding: This project was supported by subcontract number NJII 380G15 and funding opportunity number CMS-1L1-15-003 from the US Department of Health \& Human Services, Centers for Medicare \& Medicaid Services.

Prior presentation: Findings have been previously presented at the 47th NAPCRG Annual Meeting, Toronto, Canada, November 16 to 19, 2019.

Conflict of interest: None.
Joy in medical practice is an important marker of clinician satisfaction related to structural and cultural aspects of the practice. ${ }^{2}$ Clinicians give high ratings to practices with a slow pace, good communication among teams, high level of trust in the organization, and value alignment with the organization. ${ }^{2}$ Clinicians with high satisfaction scores are likely to have lower likelihood of leaving a practice. Further, clinician trust in organization can be improved with increasing control over workload. ${ }^{3}$

Burnout is defined as a syndrome of emotional exhaustion, depersonalization, and reduced personal accomplishment. ${ }^{4}$ Based on the most recent WHO definition, burnout is a syndrome conceptualized as resulting from the workplace and is characterized by

Corresponding author: Niharika Khanna, MD, MBBS, DGO, Department of Family and Community Medicine, Section on Population Health, University of Maryland School of Medicine, 29 S. Paca Street, Baltimore, MD 21201 (E-mail: nkhanna@som.umaryland.edu). 
3 dimensions: (1) feelings of energy depletion or exhaustion, (2) increased mental distance from one's job or feelings of negativism or cynicism related to one's job, and (3) reduced professional efficacy. ${ }^{5}$ Clinician burnout in US physicians remains high, and satisfaction with work-life balance is low. 6,7 Burnout may lead to increased risk for patient safety incidents and low professionalism, especially in early career and resident physicians. $^{8}$

The Centers for Medicare and Medicaid (CMS) Transforming Clinical Practice Initiative (TCPI) funded the Garden Practice Transformation Network (GPTN) for Maryland to provide coaching and educational training in practice transformation and quality improvements. CMS prescribed a practice transformation process that utilized a practice assessment tool (PAT) that included 25 elements to guide change. This tool was administered by the practice coaches at baseline and quarterly thereafter until the practice achieved change measurable as phases 1,2 3,4, and 5. At phase 5 practices were deemed transformed and ready for future participation in value-based models of care delivery. ${ }^{9}$

The PAT included a measure of "joy in work" for practice clinicians and staff. However, the exact measurement method for "joy in work" was not prescribed in the CMS TCPI change package, thus encouraging innovation by the Practice Transformation Networks (PTNs). The goal was to provide practices with a reliable, short tool to assess joy versus burnout in their clinicians and staff and to identify action items. We utilized the following hypothesis in selecting a measurement tool: If a practice understands the perception of providers and staff regarding joy in work, then they will initiate steps to address the reasons for lack of joy to prevent burnout.

Several validated instruments for measuring burnout exist, with the Maslach Burnout Inventory (MBI) being the most commonly used. ${ }^{4,10}$ Recently, a Mini $Z$ survey was introduced as a quick and convenient method of measuring burnout and burnout drivers. ${ }^{11}$ The GPTN team in Maryland selected the Mini $Z$ survey tool to study burnout in clinicians and staff and identify remediable predictors of burnout among GPTN-Maryland practices.

\section{Methods}

The study has been approved by the University of Maryland Institutional Review Board (protocol HP-00077713, approved December 13, 2018).

\section{Study Design}

The design of the study was cross sectional.

\section{Participants/Setting}

Community-based practices were recruited to participate in the GPTN. Twenty-one primary care practices with 30 sites, 23 specialty practices with 54 sites, and 4 Federally Qualified Health Centers with 25 sites participated in the GPTN-Maryland program from 2015 to $2019 .{ }^{12}$ The program leadership in Maryland was housed at the University of Maryland School of Medicine and provided coaching, mentoring, quality improvement, and assistance to prepare practices for future participation in value-based payment models. ${ }^{12,13}$

\section{Mini Z Survey Tool}

The survey includes a single-item burnout assessment that was adapted from Freeborn's tedium index and internally and externally validated against the MBI in several studies. ${ }^{11,14,15}$ The Mini $Z$ also includes 7 items measuring potential burnout drivers, 2 additional outcomes (job satisfaction and stress), and an open-ended question adapted from the Physician Worklife Survey and Minimizing Error, Maximizing Outcome (MEMO) study. ${ }^{11,14,15}$ Response to each item ranged from 1 to 5 (eg, strongly disagree to strongly agree). Additional factors evaluated in the survey included role, practice ownership status, practice specialty, and practice size.

\section{Data Collection}

The survey was distributed to the GPTNMaryland providers via e-mail using the Qualtrics platform during November 2018 to July 2019. For the providers who did not respond to the electronic survey, as well as all clinical and administrative support staff, a hard copy was distributed by the GPTN coaches.

\section{Data Analysis}

Data were analyzed using SAS 9.4 and SAS JMP Pro 13 software (Cary, NC). An internal consistency of the Mini $\mathrm{Z}$ was assessed using Cronbach's $\alpha$ coefficient; values 0.8 or greater indicated good scale reliability. Depending on the distributions and a context, the items were either recoded as categorical variables or used to create a continuous scale. In the latter case, raw scores from selected items were summed and 
converted into a 100-point score. Exploratory factor analysis was based on a principal component factoring method. ${ }^{16}$ Continuous variables were analyzed using 2-sided $t$ test; categorical variables were analyzed using 2-sided Fisher's exact test. Association between presence of burnout and burnout drivers was assessed using a generalized estimating equation regression model for ordinal outcome, which accounted for the correlation of the responses within the same practice. Level of significance was set at 2-sided $\alpha=0.05$.

\section{Results}

\section{Study Population}

Out of 514 surveys distributed, 232 were send to clinicians, and 276 were distributed among staff members. Among 181 received responses, 75 were from clinicians, and 105 from staff (response rate $32 \%$ and $38 \%$, respectively); 166 surveys without missing data on Mini $\mathrm{Z}$ items were used for the analysis (126 hard copy versions and 40 electronic responses). Clinicians and clinical and administrative staff from 36 practices provided responses, including 15 primary care, 17 specialty, and 4 large multispecialty practices. Other characteristics of the responder population are shown in Table 1.

Table 1. Characteristics of the Garden Practice Transformation Network Maryland Clinicians and Staff Who Participated in the Mini Z Survey $(n=166)$

\begin{tabular}{llrl}
\hline Responders' Characteristics & $\mathrm{N}$ & $(\%)$ \\
\hline Role, ${ }^{*} \mathrm{~N}(\%)$ & Providers & 61 & $(36.7 \%)$ \\
& Clinical staff & 27 & $(16.3 \%)$ \\
& Administrative & 67 & $(40.4 \%)$ \\
& Unknown & 11 & $(6.6 \%)$ \\
Ownership, N (\%) & Employed & 129 & $(78.7 \%)$ \\
& Owner & 35 & $(21.3 \%)$ \\
Practice size, ${ }^{\dagger} \mathrm{N}(\%)$ & Solo & 19 & $(11.5 \%)$ \\
& 2 to 5 & 71 & $(42.8 \%)$ \\
& 6 to 10 & 30 & $(18.1 \%)$ \\
& $11+$ & 46 & $(27.7 \%)$ \\
Practice type ${ }^{\ddagger} \mathrm{N}(\%)$ & Primary care & 42 & $(25.3 \%)$ \\
& Specialist & 124 & $(74.7 \%)$ \\
\hline
\end{tabular}

*Providers: MD/DO, CRNP, PA, PT; clinical staff: RN, MA.

${ }^{\dagger}$ Number of prescribing providers.

${ }^{\text {F}}$ Specialists included allergy and immunology, cardiology, dermatology, gastroenterology, ophthalmology, orthopedics, psychiatry.
Figure 1. Prevalence of burnout symptoms in community practices participating in the Garden Practice Transformation Network GPTN-Maryland Mini Z survey $(n=166)$. Numbers on the pie chart are number (percent) of participants in corresponding strata.

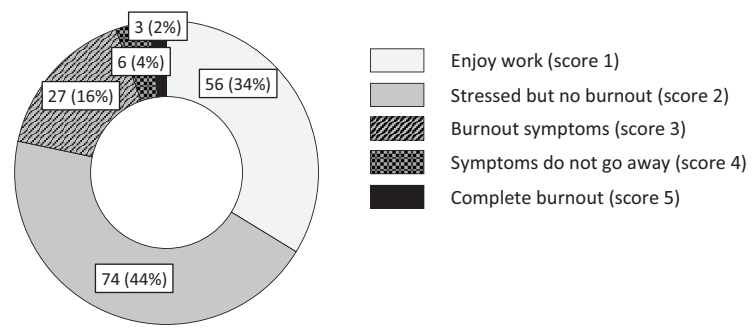

\section{Burnout}

The distribution of the responses to the burnout outcome measure is depicted in Figure 1. Among responders, 74 (44\%) experienced stress but no burnout, and 56 (34\%) reported enjoying their work (Figure 1). Symptoms of burnout were reported by 27 (16\%) responders, and 3 responders (2\%) reported to be completely burned out. The responses with scores 3 to 5 were combined for the downstream analyses, ${ }^{17}$ with $22 \%$ of responders experiencing at least some symptoms of burnout. There were no statistically significant differences in the prevalence of burnout symptoms depending on the responder role, ownership status, practice size, or practice specialty (Appendix Table 1).

\section{Burnout Drivers}

Among 7 potential burnout drivers of the Mini Z, 5 (low control over workload, insufficient time for documentation, hectic/chaotic environment, lack of value alignment with leadership, and inefficient teamwork) were significantly correlated with the presence of burnout symptoms, with a Spearman's correlation coefficient varying between -0.32 and -0.59 (Table 2). Correlation of the electronic health record (EHR) use-related factors (excessive time with EHR at home, EHR proficiency) with burnout symptoms was low and was not statistically significant (Table 2). Low overall job satisfaction also was highly correlated with burnout (Table 2).

Higher proportion of clinicians reported insufficient time for documentation, excessive EHR use at home, and lower EHR proficiency compared with the staff (Appendix Table 2). However, correlation between EHR use and the presence of burnout was 
Table 2. Spearman's Correlation Coefficients of Mini Z Items in the Garden Practice Transformation Network Maryland Clinicians and Staff $(\mathrm{n}=166)$

\begin{tabular}{|c|c|c|c|c|c|c|c|c|}
\hline & $\begin{array}{c}\text { Job } \\
\text { Satisfaction }\end{array}$ & Control & Time & Pace* & Values & Team & $\begin{array}{l}\text { EHR at } \\
\text { Home }\end{array}$ & EHR Use \\
\hline Burnout & $\begin{array}{c}0.5922 \\
<0.0001\end{array}$ & $\begin{array}{r}-0.4935 \\
<0.0001\end{array}$ & $\begin{array}{r}-0.4248 \\
<0.0001\end{array}$ & $\begin{array}{r}-0.3224 \\
<0.0001\end{array}$ & $\begin{array}{r}-0.3266 \\
<0.0001\end{array}$ & $\begin{array}{r}-0.3938 \\
<0.0001\end{array}$ & $\begin{array}{r}-0.0707 \\
0.3654\end{array}$ & $\begin{array}{r}-0.1122 \\
0.1503\end{array}$ \\
\hline Job satisfaction & 1.000 & $\begin{array}{l}0.4760 \\
<0.0001\end{array}$ & $\begin{array}{l}0.3914 \\
<0.0001\end{array}$ & $\begin{array}{c}0.2410 \\
0.0018\end{array}$ & $\begin{array}{l}0.4954 \\
<0.0001\end{array}$ & $\begin{array}{l}0.4721 \\
<0.0001\end{array}$ & $\begin{array}{c}0.0301 \\
0.7004\end{array}$ & $\begin{array}{c}0.2277 \\
0.0032\end{array}$ \\
\hline Control & & 1.000 & $\begin{array}{l}0.6363 \\
<0.0001\end{array}$ & $\begin{array}{c}0.2118 \\
0.0062\end{array}$ & $\begin{array}{l}0.4428 \\
<0.0001\end{array}$ & $\begin{array}{l}0.4592 \\
<0.0001\end{array}$ & $\begin{array}{c}0.1823 \\
0.0187\end{array}$ & $\begin{array}{l}0.3048 \\
<0.0001\end{array}$ \\
\hline Time & & & 1.000 & $\begin{array}{r}0.08386 \\
0.2827\end{array}$ & $\begin{array}{l}0.32118 \\
<0.0001\end{array}$ & $\begin{array}{l}0.36644 \\
<0.0001\end{array}$ & $\begin{array}{r}0.28568 \\
0.0002\end{array}$ & $\begin{array}{r}0.19625 \\
0.0113\end{array}$ \\
\hline Pace* & & & & 1.000 & $\begin{array}{l}0.173 \\
0.0259\end{array}$ & $\begin{array}{l}0.201 \\
0.0093\end{array}$ & $\begin{array}{c}-0.172 \\
0.0263\end{array}$ & $\begin{array}{c}-0.190 \\
0.0142\end{array}$ \\
\hline Value & & & & & 1.000 & $\begin{array}{l}0.5723 \\
<0.0001\end{array}$ & $\begin{array}{r}-0.0001 \\
0.9987\end{array}$ & $\begin{array}{c}0.1940 \\
0.0122\end{array}$ \\
\hline Team & & & & & & 1.000 & $\begin{array}{r}-0.0373 \\
0.6334\end{array}$ & $\begin{array}{c}0.1692 \\
0.0293\end{array}$ \\
\hline EHR at home & & & & & & & 1.000 & $\begin{array}{l}0.2273 \\
0.0032\end{array}$ \\
\hline
\end{tabular}

Spearman's correlation coefficients and corresponding $P$ values are shown. A 5-item burnout scale was coded so that the lowest score corresponded to the lowest burnout level (enjoyed work), and highest score corresponded to the highest level of burnout. The burnout drivers were coded so that score 1 corresponded to the lowest level of positive experience and score 5 corresponded to the highest level of positive experience, and recoded if necessary*. Mini Z burnout driver questions were formulated as followed: "Job satisfaction"- "Overall, I am satisfied with my current job, Strongly Disagree...Strongly Agree"; "Control"- "My control over workload is Poor...Optimal"; "Time"_-"Sufficiency of time for documentation is Poor...Optimal"; "Pace"—-Which number best describes the atmosphere in your primary work area? Calm...Hectic/Chaotic"; "Values"—_My professional values are well aligned with those in my department leaders, Strongly Disagree... Strongly Agree"; "Team"- "The degree to which my care team works efficiently together is Poor... Optimal"; "EHR at home"- "The amount of time I spend on the electronic medical records (EHR) at home is Excessive. . Optimal/None"; "EHR use"- "My proficiency with EHR use is Poor...Optimal."

*Item "Pace" was reverse coded.

low and not statistically significant in both groups (data not shown).

The internal consistency of the 7-item predictor scale was low (Cronbach's $\alpha$ 0.67). After removing 2 items related to EHR use, the coefficient increased to 0.74 for a 5 -item scale. Internal consistency of the scale increased further after including an overall job satisfaction as a sixth item (Cronbach's $\alpha 0.79$ ), suggesting good reliability of the scale. Similar results were obtained when the responses from providers and staff were analyzed separately (data not shown). Raw scores from these 6 items were summed and converted into a 100-point score (time constraints/ teamwork, or T/T score).

To uncover the underlying structure of the $\mathrm{T} / \mathrm{T}$ score, we conducted an exploratory factor analysis. Control over workload together with sufficient time for documentation had the highest loading on factor 1. Value alignment and teamwork had the highest loading on factor 2 . An overall job satisfaction had approximately the same loading on factors 1 and 2, whereas atmosphere in the primary work environment had the highest loading on factor 3 . Overall, these 3 factors explained $78 \%$ variance in the responses to the items composing the $\mathrm{T} / \mathrm{T}$ score (Figure 2 and data not shown).

In bivariate analysis, the $\mathrm{T} / \mathrm{T}$ score was significantly associated with the symptoms of burnout. The $\mathrm{T} / \mathrm{T}$ score for the participants who enjoyed their work was $76.6 \pm 10.4$ points compared with $62.4 \pm 12.9$ points for responders who experienced stress without burnout and $48.6 \pm 18.0$ points for those who experienced burnout symptoms (2-sided $t$ test $P<.0001)$. The association between $\mathrm{T} / \mathrm{T}$ score and burnout symptoms was also assessed using an ordinal logistic regression model. Initially, responders' characteristics (Table 1) and EHRrelated responses were considered as covariates in the multivariable regression model; however, none of these factors except T/T score was significantly associated with symptoms of burnout. The assumption of odds proportionality was met (Score test $P=.1257)$. The predicted probability of burnout derived from the ordinal logistic regression model 
Figure 2. Contribution of Mini $Z$ burnout drivers to the underlying structure of the time constraints/teamwork score (T/T) score. Data for 166 participants of the Garden Practice Transformation Network (GPTN)-Maryland Mini $Z$ survey are shown. Exploratory factor analysis of the T/T score was conducted based on a principal component factoring method. Numbers on the graph correspond to the percent of variance in the T/T score explained by each factor.

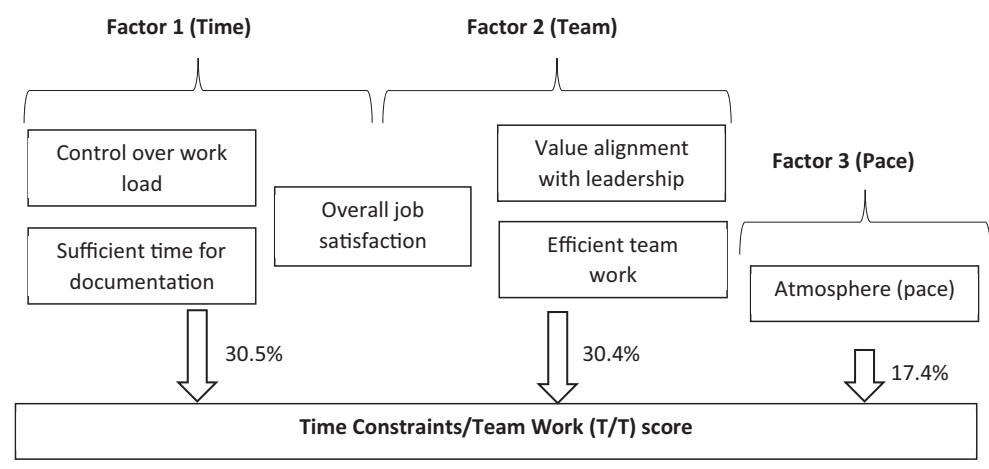

is shown in Figure 3 Accounting for the clustering effect of the practice, the odds of moving from the group who experienced burnout symptoms to the group who either was stressed or enjoyed their work increased by $10 \%$ as the $\mathrm{T} / \mathrm{T}$ score increased by 1 unit $(\mathrm{OR}=1.1,95 \% \mathrm{CI}, 1.07,1.13, P<.0001)$. Similarly, T/T score increase by 1 unit was associated with $10 \%$ increase in the odds of moving from the group experiencing burnout or stress to the group of those who found "joy in work."

Figure 3. Association between predicted probability of burnout and time constraints/teamwork score (T/T) score. Predicted probabilities of burnout derived from the ordinal logistic regression model are shown for 166 participants of the Garden Practice Transformation Network (GPTN)-Maryland Mini Z survey. Gray-shaded areas on the graph define $\mathbf{9 5 \%}$ confidence intervals.

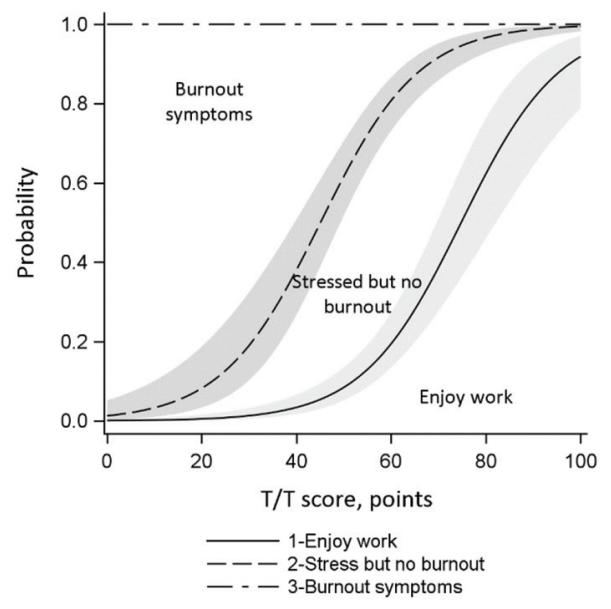

\section{Responses to Open-Ended Questions}

We also conducted a basic word analysis of the responses provided to open-ended questions about possible drivers of burnout and ways to avoid it. The data are presented in a Word Cloud in Appendix Figure 1 The most frequent words used in the text were patients, followed by time and stress. The 4 most frequent phrases were "paperwork," "patient care," "quality measures," and "time management." A quote from one of the responders summarized the challenging experience of the community providers, especially solo providers: "Stresses are to see enough patients during the day to keep the practice successful, to not get too far behind seeing patients, to be thorough and to finish documentation as soon as last patient leaves. That never happens. I spend 1.5-2 hours a night finishing notes." Other comments of interest were related to the need for appropriate staffing and proper training of the ancillary staff to handle difficult patients (data not shown).

\section{Discussion}

Joy in work is associated with greater productivity, lower costs, longevity on the job, team participation, and higher quality of work. ${ }^{18}$ It is also a measure of wellness of the workforce and of the health systems supports provided to clinicians and practice personnel.

In this study, we explored the prevalence of burnout and potential drivers of burnout in GPTN-Maryland ambulatory practices using a 
Mini $Z$ survey. The prevalence of burnout in our population was $22 \%$. This estimate is lower compared with the US national data that estimated prevalence of burnout in providers between $40 \%$ and $54 \%{ }^{19,20}$ and in nurses between $35 \%$ and $45 \% .^{21}$ This difference may be due to the supports provided to the GPTN practices making a positive change in their practices, particularly teamwork. Practice transformation and teamwork have been previously demonstrated to positively impact physician satisfaction with work. ${ }^{1}$ In addition, a Mini Z burnout measure does not query in detail the multidimensional nature of burnout. In the study by Olson et al., prevalence of burnout measured by 22-point MBI survey was higher compared with the Mini $Z$ estimate (56.6\% and 39.0\% respectively). ${ }^{17}$

Initial assessment of correlations between burnout predictors and analysis of the internal consistency of the scale composed from these predictors supported strongly the need for modifications of the previously identified subscales. We identified a scale composed of 6 Mini $\mathrm{Z}$ burnout predictors that were related to time constraints and teamwork (overall job satisfaction, control over the workload, sufficient time for documentation, hectic/chaotic environment, value alignment with leadership, and efficient teamwork). A continuous T/T score constructed from these predictors was significantly associated with burnout symptoms, with higher scores indicating lower probability of burnout. While sufficient time for documentation was one of the most important predictors of burnout, the items related to EHR use (excessive use of EHR at home and EHR proficiency) were not significantly associated with burnout in our study. These findings contradict existing data about EHR as one of the major sources of burnout among physicians. ${ }^{17,22,23}$ This discrepancy may be due to precise question formulation in the Mini $Z$ survey and its interpretation by the responders. In our practices, many participants, especially support staff, did not use the EHR at home, thus inflating the score. In addition, general proficiency with EHR use may not be a good indicator of burnout, because it does not specify the task performed and its complexity, thus responses to this question may be subjective. Based on the comments from the GPTN coaches, the major source of stress related to EHR use in practices was the lack of support from EHR vendors to accomplish quality measurement and reporting requirements.
The Mini $Z$ survey was initially developed to assess burnout among clinicians. Because of the TCPI requirements to assess "joy in work" among both clinicians and staff, we used this survey in both groups. Our results showed that a higher proportion of clinicians reported insufficient time for documentation, excessive EHR use at home, and lower EHR proficiency compared with the staff. However, association between EHR use and the presence of burnout was not statistically significant in both groups. Although the physicians and clinical and administrative staff could be very different in their perception of burnout, our data show that Mini Z (specifically T/T score) could be a useful tool to quickly assess burnout and burnout drivers in a health care organization, especially the factors related to the effective organizational structure and supportive teamwork. Further studies are needed to determine how well the T/T score composed of selected Mini Z items could predict burnout measured by different methods. It would also be important to identify other actionable predictors of burnout in the clinical practices.

Individual characteristics of responders such as personal resilience should also be considered as factors contributing to burnout. ${ }^{24}$ In our study, 35\% of responders enjoyed their work, and $85 \%$ of them worked in the same practices as those who presented with burnout symptoms. Interestingly, the internal consistency of the Mini $\mathrm{Z}$ burnout driver scale increased after including the overall job satisfaction measure, which is considered to be a function of professional well-being rather than a burnout driver. ${ }^{25,26}$ The survey conducted recently in providers working in psychiatric services has included screening for burnout, anxiety, and depression as separate measures. ${ }^{27}$ Although anxiety, depression, and burnout may coexist, it is important to consider joy and burnout as separate entities, with personal and system drivers.

Recent recommendations from the National Academies of Sciences, Engineering, and Medicine are based on the occupational framework that views and addresses burnout as a system issue rather than personal mental health diagnosis. ${ }^{23}$ System-level changes could be applied to large health care organizations, including creating a learning environment, teamwork, greater control over workload, and welldesigned EHR systems that meet all current reporting requirements. At the organizational level, communication between clinicians and staff, changes in 
workflow, and quality improvement could be effective in preventing and reducing burnout. ${ }^{28}$ The GPTN provided systems supports to participating practices with coaching, reporting quality metrics, quality improvement, and education supports. Without systems supports, such changes are difficult to apply in small community practices with limited resources. The needs of solo practitioners with limited ancillary staff are not completely addressed in the current framework.

One of the major external factors contributing to burnout in community practices is highly demanding reporting requirements that are not always accommodated by the practice's EHR system. Recently, CMS proposed several measures that address provider burnout due to the excessive paperwork tied to outdated billing practices. ${ }^{29}$ In addition, after-hours time spent by providers on answering patients' texts, e-mails, and e-portal messages, which provide patient access, needs consideration for reimbursement to the physician and also needs to be recognized as improving quality of care delivery.

Our study has several limitations. First, the severity of burnout could be underestimated because, despite the anonymous nature of the survey, individuals with more severe symptoms of burnout might be less likely to participate in the survey. Second, there was an imbalance in the provider/ staff ratio in our study population. In some practices, providers refused to participate in the survey, whereas in other practices, a request for staff participation was denied. Finally, the engagement of the practices in the GPTN-Maryland was voluntary, thus limiting generalizability of the findings.

\section{Conclusion}

Using the impetus provided by CMS, the GPTNMaryland team identified a methodology to assess "joy in work" in participating practices to identify impactable elements to reduce burnout in practice personnel. The Mini $\mathrm{Z}$ provided a tool for assessment of joy and burnout in both clinicians and staff. Further characterization of these observations led to an understanding of the major factors that impact burnout, specifically time constraints and teamwork. These observations have been presented in a $\mathrm{T} / \mathrm{T}$ score to provide practices with a starting point to address burnout in their practice. Assessment of impactable factors predicting burnout in smaller practices is possible using shorter screening tools such as the Mini Z.

We thank all participants of the survey, the GPTN-Maryland coaches and management team for their help with survey administration, collection of data, data entry, and data management.

To see this article online, please go to: http://jabfm.org/content/ 33/3/357.full.

\section{References}

1. Reid RJ, Coleman K, Johnson EA, et al. The Group Health medical home at year two: cost savings, higher patient satisfaction, and less burnout for providers. Health Aff (Millwood) 2010;29:835-43.

2. Linzer M, Sinsky CA, Poplau S, Brown R, Williams E, Healthy Work Place Investigators. Joy in medical practice: clinician satisfaction in the Healthy Work Place trial. Health Aff (Millwood) 2017;36: 1808-14.

3. Linzer M, Poplau S, Prasad K, et al. Characteristics of health care organizations associated with clinician trust: results from the Healthy Work Place Study. JAMA Netw Open 2019;2:e196201.

4. Maslach C, Jackson SE, Leiter MP. Maslach Burnout Inventory: third edition. In: Evaluating stress: a book of resources. Lanham (MD): Scarecrow Education; 1997. p. 191-218.

5. WHO [Internet]. Burn-out an "occupational phenomenon": International Classification of Diseases [cited 11 Nov 2019]. Available from: https://www. who.int/mental_health/evidence/burn-out.

6. Dzau VJ, Kirch DG, Nasca TJ. To care is humancollectively confronting the clinician-burnout crisis. N Engl J Med 2018;378:312-4.

7. Shanafelt TD, Hasan O, Dyrbye LN, et al. Changes in burnout and satisfaction with work-life balance in physicians and the general US working population between 2011 and 2014. Mayo Clin Proc 2015;90:1600-13.

8. Panagioti M, Geraghty $\mathrm{K}$, Johnson $\mathrm{J}$, et al. Association between physician burnout and patient safety, professionalism, and patient satisfaction: a systematic review and meta-analysis. JAMA Intern Med 2018;178:1317-30.

9. Garden Practice Transformation Network-NJII [Internet]. 2019 [cited 16 Oct 2019]. Available from: https://njii.com/ptn/.

10. Schaufeli WB, Leiter MP, Maslach C. Burnout: 35 years of research and practice. Career Dev Int 2009;14:204-20.

11. Linzer M, Poplau S, Babbott S, et al. Worklife and wellness in academic general internal medicine: results from a national survey. J Gen Intern Med 2016;31:1004-10. 
12. Khanna N, Gritzer L, Klyushnenkova E, et al. Practice transformation analytics dashboard for clinician engagement. Ann Fam Med 2019;17:S73-S76.

13. Gritzer L, Davenport M, Dark M, Khanna N. Coaching small primary care practices to use patient portals. Ann Fam Med 2019;17:S83-S83.

14. Linzer M, Visser MR, Oort FJ, et al. Predicting and preventing physician burnout: results from the United States and the Netherlands. Am J Med 2001;111:170-5.

15. Shimotsu SPS, Linzer M. Validation of a brief clinician survey to reduce clinician burnout. J Gen Intern Med 2015;30:S79-S80.

16. JMP [Internet]. Overview of the factor analysis platform. 2019 [cited 27 Nov 2019]. Available from: https://www.jmp.com/support/help/14-2/overviewof-the-factor-analysis-platform.shtml.

17. Olson K, Sinsky C, Rinne ST, et al. Cross-sectional survey of workplace stressors associated with physician burnout measured by the Mini- $Z$ and the Maslach Burnout Inventory. Stress Health 2019;35: 157-75.

18. Han S, Shanafelt TD, Sinsky CA, et al. Estimating the attributable cost of physician burnout in the United States. Ann Intern Med 2019;170:784-90.

19. Shanafelt TD, Noseworthy JH. Executive leadership and physician well-being: nine organizational strategies to promote engagement and reduce burnout. Mayo Clinic Proc 2017;92(1):129-46.

20. Shanafelt TD, West CP, Sinsky C, et al. Changes in burnout and satisfaction with work-life integration in physicians and the general US working population between 2011 and 2017. Mayo Clin Proc. 2019;94:1681-1694.

21. Moss M, Good VS, Gozal D, Kleinpell R, Sessler CN. An official Critical Care Societies collaborative statement: burnout syndrome in critical care health care professionals: a call for action. Am J Crit Care 2016;25:368-76.

22. Melnick ER, Dyrbye LN, Sinsky CA, et al. The association between perceived electronic health record usability and professional burnout among US physicians. Mayo Clin Proc 2020; 95:476-87.

23. National Academies of Sciences, Engineering, and Medicine. Taking action against clinician burnout: a systems approach to professional well-being. Washington: National Academies Press; 2019.

24. Szanton SL, Gill JM. Facilitating resilience using a society-to-cells framework: a theory of nursing essentials applied to research and practice. ANS Adv Nurs Sci 2010;33:329-43.

25. Doble SE, Santha JC. Occupational well-being: rethinking occupational therapy outcomes. Can J Occup Ther 2008;75:184-90.

26. Chari R, Chang C-C, Sauter SL, et al. Expanding the paradigm of occupational safety and health: a new framework for worker well-being. J Occup Environ Med 2018;60:589-93.

27. Hardy P, Costemale-Lacoste J-F, Trichard C, et al. Comparison of burnout, anxiety and depressive syndromes in hospital psychiatrists and other physicians: Results from the ESTEM study. Psychiatry Res 2019;284:112662.

28. Linzer M, Poplau S, Grossman E, et al. A cluster randomized trial of interventions to improve work conditions and clinician burnout in primary care: results from the Healthy Work Place (HWP) Study. J Gen Intern Med 2015;30:1105-11.

29. CMS.gov [Internet]. CMS finalizes changes to advance innovation, restore focus on patients. 2018 [cited 5 Nov 2019]. Available from: https://www. cms.gov/newsroom/press-releases/cms-finalizeschanges-advance-innovation-restore-focus-patients. 
Appendix Table 1. Association between Responders' Characteristics and Burnout Symptoms

\begin{tabular}{|c|c|c|c|c|c|c|c|c|}
\hline & & \multicolumn{2}{|c|}{$\begin{array}{l}\text { Enjoy Work } \\
\quad(\mathrm{n}=66)\end{array}$} & \multicolumn{2}{|c|}{$\begin{array}{l}\text { Stress, No Burnout } \\
\qquad(\mathrm{n}=74)\end{array}$} & \multicolumn{2}{|c|}{$\begin{array}{l}\text { Burnout } \\
(\mathrm{n}=36)\end{array}$} & \multirow[b]{2}{*}{$P$ Value* } \\
\hline \multicolumn{2}{|c|}{ Responders' Characteristics } & $\mathrm{N}$ & $\%$ & $\mathrm{~N}$ & $\%$ & $\mathrm{~N}$ & $\%$ & \\
\hline \multirow[t]{4}{*}{ Role, ${ }^{\dagger} \mathrm{N}(\%)$} & Clinicians & 17 & $(27.9 \%)$ & 28 & $(45.9 \%)$ & 16 & $(26.2 \%)$ & 0.4600 \\
\hline & Clinical staff & 12 & $(44.4 \%)$ & 12 & $(44.4 \%)$ & 3 & $(11.1 \%)$ & \\
\hline & Administrative & 23 & $(34.3 \%)$ & 31 & $(46.3 \%)$ & 13 & $(19.4 \%)$ & \\
\hline & Unknown & 4 & $(36.4 \%)$ & 3 & $(27.3 \%)$ & 4 & $(36.4 \%)$ & \\
\hline \multirow[t]{2}{*}{ Ownership, N (\%) } & Employed & 45 & $(34.9 \%)$ & 54 & $(41.9 \%)$ & 30 & $(23.3 \%)$ & 0.4561 \\
\hline & Owner & 10 & $(28.6 \%)$ & 19 & $(54.3 \%)$ & 6 & $(17.1 \%)$ & \\
\hline \multirow[t]{4}{*}{ Practice size ${ }^{\ddagger} \mathrm{N}(\%)$} & Solo & 7 & $(36.8 \%)$ & 9 & $(47.4 \%)$ & 3 & $(15.8 \%)$ & 0.4128 \\
\hline & 2 to 5 & 21 & $(29.6 \%)$ & 37 & $(52.1 \%)$ & 13 & $(18.3 \%)$ & \\
\hline & 6 to 10 & 9 & $(30.0 \%)$ & 14 & $(46.7 \%)$ & 7 & $(23.3 \%)$ & \\
\hline & $11+$ & 19 & $(41.3 \%)$ & 14 & $(30.4 \%)$ & 13 & $(28.3 \%)$ & \\
\hline \multirow[t]{2}{*}{ Practice type, ${ }^{\S} \mathrm{N}(\%)$} & Primary care & 14 & $(33.3 \%)$ & 17 & $(40.5 \%)$ & 11 & $(26.2 \%)$ & 0.6989 \\
\hline & Specialist & 42 & $(33.9 \%)$ & 57 & $(46.0 \%)$ & 25 & $(20.2 \%)$ & \\
\hline
\end{tabular}

Data for 166 clinicians and staff who participated in the Garden Practice Transformation Network (GPTN)-Maryland Mini Z survey are shown.

*2-sided Fisher's exact test.

${ }^{\dagger}$ Providers: MD/DO, CRNP, PA; clinical staff: RN, MA.

${ }^{\ddagger}$ Number of prescribing providers.

${ }^{\$}$ Specialists included allergy and immunology, cardiology, dermatology, gastroenterology, ophthalmology, orthopedics, psychiatry. 
Appendix Table 2. Association between Mini Z Burnout Drivers and the Responder's Role

\begin{tabular}{|c|c|c|c|c|c|c|}
\hline \multirow[b]{2}{*}{ Mini Z Items } & & \multicolumn{2}{|c|}{$\begin{array}{c}\text { Provider } \\
(\mathrm{n}=61)\end{array}$} & \multicolumn{2}{|c|}{$\begin{array}{c}\text { Staff } \\
(\mathrm{n}=105)\end{array}$} & \multirow[b]{2}{*}{$P$ Value* } \\
\hline & & $\mathrm{N}$ & $\%$ & $\mathrm{~N}$ & $\%$ & \\
\hline \multirow{5}{*}{$\begin{array}{l}\text { Overall, I am satisfied } \\
\text { with my current job: }\end{array}$} & Strongly disagree & 1 & $(1.6 \%)$ & 1 & $(1.0 \%)$ & \multirow[t]{5}{*}{$0.6825^{\mathrm{F}}$} \\
\hline & Disagree & 4 & $(6.6 \%)$ & 5 & $(4.8 \%)$ & \\
\hline & Neutral & 10 & $(16.4 \%)$ & 16 & $(15.2 \%)$ & \\
\hline & Agree & 25 & $(41.0 \%)$ & 54 & $(51.4 \%)$ & \\
\hline & Strongly agree & 21 & $(34.4 \%)$ & 29 & $(27.6 \%)$ & \\
\hline \multirow{5}{*}{$\begin{array}{l}\text { My control over my } \\
\text { workload is: }\end{array}$} & Poor & 3 & $(4.9 \%)$ & 2 & $(1.9 \%)$ & \multirow[t]{5}{*}{0.1379} \\
\hline & Marginal & 13 & $(21.3 \%)$ & 12 & $(11.4 \%)$ & \\
\hline & Satisfactory & 14 & $(23.0 \%)$ & 23 & $(21.9 \%)$ & \\
\hline & Good & 22 & $(36.1 \%)$ & 57 & $(54.3 \%)$ & \\
\hline & Optimal & 9 & $(14.8 \%)$ & 11 & $(10.5 \%)$ & \\
\hline \multirow{5}{*}{$\begin{array}{l}\text { Sufficiency of time for } \\
\text { documentation is: }\end{array}$} & Poor & 8 & $(13.1 \%)$ & 3 & $(2.9 \%)$ & \multirow[t]{5}{*}{0.0138} \\
\hline & Marginal & 14 & $(23.0 \%$ & 15 & $(14.3 \%)$ & \\
\hline & Satisfactory & 16 & $(26.2 \%)$ & 26 & $(24.8 \%)$ & \\
\hline & Good & 21 & $(34.4 \%)$ & 48 & $(45.7 \%)$ & \\
\hline & Optimal & 2 & $(3.3 \%)$ & 13 & $(12.4 \%)$ & \\
\hline \multirow{5}{*}{$\begin{array}{l}\text { Which number best } \\
\text { describes the } \\
\text { atmosphere in your } \\
\text { primary work area? } \dagger\end{array}$} & Hectic, chaotic & 3 & $(4.9 \%)$ & 7 & $(6.7 \%)$ & \multirow[t]{5}{*}{0.3741} \\
\hline & & 12 & $(19.7 \%$ & 27 & $(25.7 \%)$ & \\
\hline & Busy, but reasonable & 33 & $(54.1 \%)$ & 60 & $(57.1 \%)$ & \\
\hline & & 6 & $(9.8 \%)$ & 4 & $(3.8 \%)$ & \\
\hline & Calm & 7 & $(11.5 \%)$ & 7 & $(6.7 \%)$ & \\
\hline \multirow{5}{*}{$\begin{array}{l}\text { My professional values } \\
\text { are well aligned with } \\
\text { those of my } \\
\text { department leaders: }\end{array}$} & Strongly disagree & 1 & $(1.6 \%)$ & 2 & $(1.9 \%)$ & \multirow[t]{5}{*}{$0.2274^{\mathrm{F}}$} \\
\hline & Disagree & 4 & $(6.6 \%)$ & 5 & $(4.8 \%)$ & \\
\hline & Neutral & 15 & $(24.6 \%)$ & 17 & $(16.2 \%)$ & \\
\hline & Agree & 19 & $(31.2 \%)$ & 51 & $(48.6 \%)$ & \\
\hline & Strongly agree & 22 & $(36.1 \%)$ & 30 & $(28.6 \%)$ & \\
\hline \multirow{5}{*}{$\begin{array}{l}\text { The degree to which my } \\
\text { care team works } \\
\text { efficiently together is: }\end{array}$} & Poor & 2 & $(3.3 \%)$ & 3 & $(2.9 \%)$ & \multirow[t]{5}{*}{0.5195} \\
\hline & Marginal & 5 & $(8.2 \%)$ & 9 & $(8.6 \%)$ & \\
\hline & Satisfactory & 8 & $(13.1 \%)$ & 25 & $(23.8 \%)$ & \\
\hline & Good & 28 & $(45.9 \%)$ & 45 & $(42.9 \%)$ & \\
\hline & Optimal & 18 & $(29.5 \%)$ & 23 & $(21.9 \%)$ & \\
\hline \multirow{5}{*}{$\begin{array}{l}\text { The amount of time I } \\
\text { spend on the } \\
\text { electronic health } \\
\text { record (EHR) at home } \\
\text { is: }\end{array}$} & Excessive & 9 & $(14.8 \%$ & 0 & $(0.0 \%)$ & \multirow[t]{5}{*}{$<0.0001$} \\
\hline & Moderately high & 16 & $(26.2 \%)$ & 4 & $(3.8 \%)$ & \\
\hline & Satisfactory & 10 & $(16.4 \%)$ & 22 & $(21.0 \%)$ & \\
\hline & Modest & 10 & $(16.4 \%)$ & 10 & $(9.5 \%)$ & \\
\hline & Minimal/none & 16 & $(26.2 \%)$ & 69 & $(65.7 \%)$ & \\
\hline \multirow{5}{*}{$\begin{array}{l}\text { My proficiency with } \\
\text { EHR use is: }\end{array}$} & Poor & 1 & $(1.6 \%)$ & 2 & $(1.9 \%)$ & \multirow[t]{5}{*}{$0.0275^{\mathrm{F}}$} \\
\hline & Marginal & 4 & $(6.6 \%)$ & 1 & $(1.0 \%)$ & \\
\hline & Satisfactory & 19 & $(31.2 \%)$ & 17 & $(16.2 \%)$ & \\
\hline & Good & 23 & $(37.7 \%)$ & 56 & $(53.3 \%)$ & \\
\hline & Optimal & 14 & $(23.0 \%)$ & 29 & $(27.6 \%)$ & \\
\hline
\end{tabular}

Data for 166 clinicians and staff who participated in the Garden Practice Transformation Network (GPTN)-Maryland Mini Z survey are shown.

${ }^{*} \chi^{2}$ test unless indicated otherwise; F: 2 -sided Fisher's exact test. $P$ values $<0.05$ are highlighted in bold.

${ }^{\dagger}$ Reverse-coded item.

EHR, electronic health record. 
Appendix Figure 1. Word cloud for the open-ended responses about possible drivers of burnout. Data for 30 clinicians and staff who participated in the Garden Practice Transformation Network (GPTN)-Maryland Mini Z survey and provided written comments are shown. The size of the word is proportionate to its use frequency.

$$
\text { Word Cloud }
$$

patient ·

work.

document.

give. school.

keep. due.

understand.

feel.

manas.

clinic.

learn.

great. care.

measure. role. excess. meet.

moth. stress.

time-

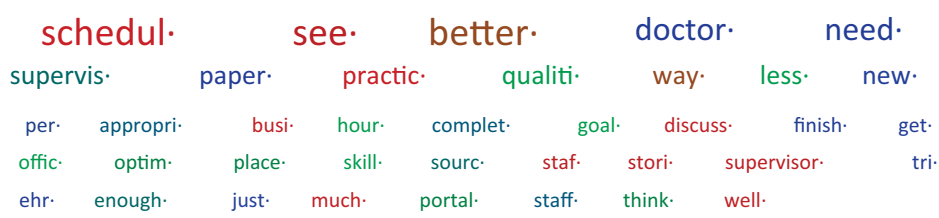

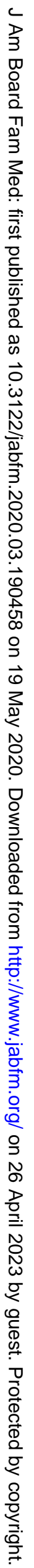

doc: 10.3122/jabfm.2020.03.190458

Identifying Remedial Predictors of Burnout

367 